\title{
The Development of Tyrosinase and Cytochrome Oxidase Activity in Mutants of Glomerella cingulata
}

\author{
Alfred S. Sussman and Clement L. Markert \\ From the Departments of Botany and Zoology, University of \\ Michigan, Ann Arbor, Michigan
}

Received January 13, 1953

\section{INTRODUCTION}

The successful use of yeast mutants in the study of the cytochrome system (1) suggested that similar techniques could be applied to the study of the synthesis of terminal oxidase systems in other organisms. With this in mind, mutants of Glomerella cingulata, which form varying amounts of color in their mycelia as a result of tyrosinase activity (2), were studied for their tyrosinase and cytochrome oxidase contents, as a function of their age in culture.

\section{Materials and Methods}

Five mutants of Glomerella cingulata with different amounts of tyrosinase activity were used in these experiments: standard type, 300, 509, 207, and 550. The standard type $\left(\mathrm{A}^{1} \mathrm{~B}^{1}\right)$ is a double mutant from the wild type; it produces scattered conidia and possesses an average amount of tyrosinase activity as compared with the other mutants. The remaining four mutants were obtained by exposing conidia of the standard type to various mutagenic radiations including ultraviolet, $x$-ray, and neutron bombardment. Genetic tests indicate that these represent single-gene changes. Mutants 300 and 509 are characterized by high tyrosinase activity, and mutants 207 and 550 have almost no such activity. In addition to the genetically altered tyrosinase activity, mutant 509 requires methionine and mutant 550 requires tryptophan for growth. The remaining mutants do not have increased nutritional requirements.

Mycelia were grown from a mass conidial inoculum on $30 \mathrm{ml}$. of complete agar medium in Petri dishes, and the cultures were then incubated at $25^{\circ} \mathrm{C}$. until used. Cf. Markert (2) for details of media preparation, culture methods, etc.

In preparing crude enzyme extracts, the mycelial mat was carefully peeled from the agar, weighed, and macerated in various suspending media with a glass homogenizer. For routine enzyme determinations the mycelial brei was centrifuged at $100 \times g$ for 15 min., after which the supernatant was collected and used. For the purpose of fractionating the enzyme extracts, further centrifuga- 
tions were performed as will be described later. The conidial brei was treated like the mycelial brei in the preparation of erude enzyme extracts.

Tyrosinase activity was determined by means of an assay using a Beckman model B spectrophotometer. The reaction mixture was composed of $1 \mathrm{ml}$. of 0.02 $M$ DL-dihydroxyphenylalanine (dopa), $0.1 \mathrm{ml}$. of the enzyme preparation, and $1.5 \mathrm{ml}$. of distilled water. The substrate was added at zero time and readings were made at $480 \mathrm{~m} \mu$ at 10 -sec. intervals. Since pigment formation was essentially linear for the first 60 sec., the change in optical density during this time was used in computing the tyrosinase activity. In order to ascertain that reducing substances were not preventing color formation, manometric check runs were made. In these, catechol was used as substrate and hydroquinone as the reducer in the manner described by Goddard (3). Very low levels of tyrosinase activity could not be detected within $5 \mathrm{~min}$. on the spectrophotometer although some visible pigmentation was frequently produced after incubation for 1-2 $\mathrm{hr}$. In such cases the symbols,+++ , and +++ were used to designate increasing amounts of activity. Failure to produce any pigmentation was designated by a zero.

Cytochrome oxidase activity was assayed manometrically using an excess of cytochrome c (Sigma) as the substrate and hydroquinone as the reducer (3). Since hydroquinone was not oxidized in the absence of cytochrome $c$, laccase was apparently not present and thus did not interfere with the tyrosinase determinations.

Standardization of the enzyme preparations was accomplished by determining the total nitrogen contents of aliquots. These determinations were made by means of a direct nesslerization after sulfuric acid and peroxide digestion, according to a modification of the method of Koch and McMeekin (4).

Growth was determined by measuring the dry weight of the mycelium obtained at various times after inoculation. The mycelium was dried at $105^{\circ} \mathrm{C}$. for $24 \mathrm{hr}$. by which time constant weight was obtained.

\section{RESULTS}

\section{The Extraction Medium}

It was early found that consistent results in the extraction of cytochrome oxidase could be obtained through the use of hypertonic solutions of disaccharides buffered with $0.067 M(1 / 15 M)$ phosphate buffer at $\mathrm{pH}$ 7.2. Of these extraction media, sucrose and maltose proved to be almost equally effective, as the results in Table I show. In subsequent determinations of both cytochrome oxidase and of tyrosinase activity, $0.5 M$ sucrose in $1 / 15 M$ phosphate buffer at $\mathrm{pH} 7.2$ was the extraction medium used.

\section{The Localization of Oxidase Activity in Enzyme Extracts}

Fractionation of the enzyme extracts was undertaken in order to localize the enzyme activity. For this purpose, $30 \%$ homogenates were 
prepared from 189 -hr. cultures and were centrifuged at $100 \times g$ for 15 min. to remove cell fragments. The supernatant was recentrifuged for $20 \mathrm{~min}$. at $5000 \times g$, and the precipitate was saved. This procedure was repeated once more by recentrifuging the supernatant from the last centrifugation for $20 \mathrm{~min}$. at $18,000 \times g$. The precipitates of the two fast centrifugations were resuspended in measured volumes of the extraction medium, and their enzyme activities were determined along with those

\section{TABLE I}

The Effect of Extraction in Sucrose or Maltose upon the Cytochrome Oxiduse Activily of Glomerella cingulala

Data compiled from 128-hr. cultures

Extraction medium ${ }^{a}$

$0.5 M$ sucrose

$0.25 M$ sucrose

$0.5 M$ maltose

$0.25 \mathrm{M}$ maltose
$Q_{\mathrm{O}_{2}}{ }^{b}$

56

54

52

44

${ }^{a}$ Each solution was made up in 1/15 $M$ phosphate buffer at $\mathrm{pH}$ 7.2.

${ }^{b}$ The $Q_{\mathrm{O}_{2}}$ was calculated as the cu.mm. $\mathrm{O}_{2}$ consumed/hr./mg. nitrogen.

\section{TABLE II}

The Localization of Cytochrome Oxidase and Tyrosinase Activity in Homogenates Prepared from Glomerella cingulata

Fraction measured

$100 \times g$ supernatant

$5000 \times g$ supernatant

$5000 \times g$ precipitate

$18,000 \times g$ supernatant

$18,000 \times g$ precipitate

\section{Cytochrome oxidase activity}

cu.mm.

76

56

14

32

15 cu.mm.
$\mathrm{O}_{2} / \mathrm{hr} . / \mathrm{mg} . \mathrm{N}$

51

39

227

25

169
Tyrosinase activity $\Delta$ opt. dens./ $\min . / 100 \mu \mathrm{g} . \mathrm{N}$

0.210

0.210

0.035

0.205

0.065

of the various supernatants. These results, given in Table II, suggest that cytochrome oxidase is localized on the particulate material of these preparations, although about $20 \%$ of the activity is present in the supernatant.

\section{The Development of Oxidase Activity}

The five mutants used in these experiments were grown on agar, and the mycelium was removed and tested for oxidase activity at intervals after inoculation. It was not possible to get enough material for testing 
from cultures younger than $48 \mathrm{hr}$. so that no results are reported during this time interval.

Figure 1 and Table III give the results of experiments performed with the standard type. It can be seen that the cytochrome oxidase activity of

TABLE III

Oxidase Activity, Dry Weight and Color Changes in the Standard Type of Glomerella cingulata

\begin{tabular}{|c|c|c|c|c|c|c|}
\hline \multirow{2}{*}{ Age } & \multirow{2}{*}{$\begin{array}{c}\text { Color of } \\
\text { mycelium }\end{array}$} & \multirow{2}{*}{$\begin{array}{l}\text { Dry wt. } \\
\text { (Expt. 3) }\end{array}$} & \multirow{2}{*}{$\begin{array}{c}\text { Tyrosinase } \\
\text { activity } \\
\text { (Expt. 3) }\end{array}$} & \multirow{2}{*}{$\begin{array}{l}\text { Rel. } \\
\text { activ. }\end{array}$} & \multicolumn{2}{|c|}{$\begin{array}{c}\text { Cytochrome } \\
\text { oxidase activity }\end{array}$} \\
\hline & & & & & $\begin{array}{c}\text { (Expt. } \\
1)\end{array}$ & (Expt. \\
\hline$h r$. & & $m g$. & $\underset{\min . / 100 \mu \mathrm{gg} .}{\Delta \text { opt } N}$ & $\%$ & \multicolumn{2}{|c|}{$\begin{array}{l}\text { cusmm. } \\
\mathrm{O}_{2} / m g \cdot N\end{array}$} \\
\hline Conidia & - & & 0.128 & 13 & 102 & 一 \\
\hline 48 & White & 223 & 0 & - & 54 & 一 \\
\hline 72 & White & 294 & 0 & - & 58 & - \\
\hline 96 & Gray & 306 & - & - & 49 & - \\
\hline 112 & - & 一 & - & - & - & 49 \\
\hline 120 & Gray & 307 & 0 & - & 20 & - \\
\hline 137 & - & - & - & 一 & - & 44 \\
\hline 143 & Dark gray & 303 & 0.306 & 32 & 50 & - \\
\hline 159 & - & - & 一 & 一 & - & 52 \\
\hline 165 & - & - & - & - & 55 & 一 \\
\hline 167 & Black & 262 & - & - & - & - \\
\hline 183 & Black & - & - & - & - & 49 \\
\hline 190 & Black & 192 & 0.721 & 75 & - & 一 \\
\hline 215 & Black & 178 & 0.955 & 100 & 51 & - \\
\hline 233 & Black & - & - & - & - & 57 \\
\hline 241 & Black & 205 & 0.894 & 93 & 一 & 一 \\
\hline 265 & Black & 180 & 0.642 & 67 & 46 & - \\
\hline 288 & Black & 136 & 0.308 & 32 & - & - \\
\hline 305 & Black & - & - & - & - & 73 \\
\hline 309 & Black & - & - & - & 56 & - \\
\hline 316 & Black & 148 & - & - & - & - \\
\hline
\end{tabular}

${ }^{a}$ Relative activity was calculated using the tyrosinase activity of the $215-\mathrm{hr}$. sample of the standard type as $100 \%$ activity.

the mycelium remained constant within the limits of experimental error, since only 2 points out of a total of 15 showed a significant deviation from the mean. Conidia showed almost twice as much cytochrome oxidase activity as did the mycelium.

However, the tyrosinase activity of the standard type presented an 
entirely different picture. Conidia show a moderate amount of tyrosinase activity, but this is lost within $48 \mathrm{hr}$. after germination. It is not until about $120 \mathrm{hr}$. after germination that tyrosinase activity reappears in the organism after which its increase is precipitous, reaching its maximum at about $190 \mathrm{hr}$. Thereafter, a rapid decrease in tyrosinase occurs but the level of such activity does not reach zero even in experiments carried out for $988 \mathrm{hr}$. after inoculation. The significance of the secondary maximum observed at about $260 \mathrm{hr}$. is doubtful, but similar maxima have been

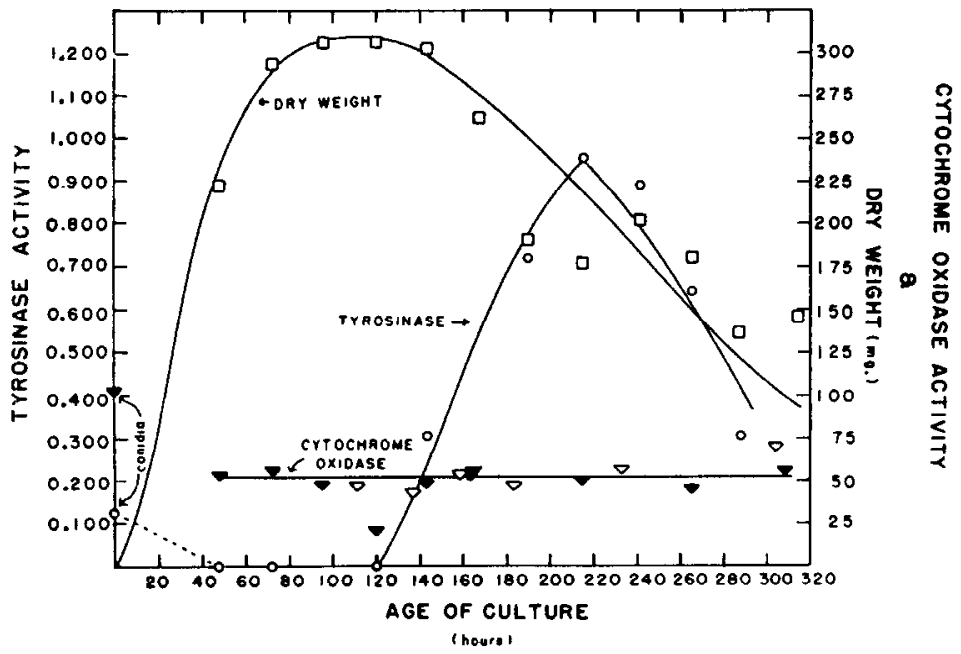

FIG. 1. The oxidase activity and dry weight changes in the standard type of Glomerella cingulata. Cytochrome oxidase activity is expressed as cu. mm. $\mathrm{O}_{2} /$ mg. $\mathrm{N}$; tyrosinase activity is expressed as $\Delta$ optical density/min./100 $\mu \mathrm{g}$. N. Legend: squares, dry weight; triangles (filled), cytochrome oxidase activity (Expt. 1); triangles (open), cytochrome oxidase activity (Expt. 2); and circles, tyrosinase activity (Expt. 3).

observed in at least four separate experiments. In relating the variations in tyrosinase activity to the growth of the fungus, as measured by its dry weight, it appears that the enzyme is not formed until after the peak of the growth curve is reached. In fact, the beginning of autolysis ${ }^{1}$ of the mycelium seems to coincide closely with the point at which tyrosinase

1 The term autolysis is used merely to describe the fact that the mycelium loses weight after the peak of growth has been reached. No lysis or liquefaction, as is observable during the autolysis of other microorganisms, was detectable in the mycelium of the Glomerella mutants used in these experiments. 
activity begins to increase rapidly. Furthermore, the formation of color in the mycelium parallels the development of tyrosinase activity (cf. Table III).

The oxidase activity of two other tyrosinase-producing mutants of Glomerella cingulata, 509 and 300, was then studied. Figures 2 and 3 give the results of the experiments using these mutants. In both cases the cytochrome oxidase activity remains constant, whereas tyrosinase activity appears only after the peak of growth has been reached. This

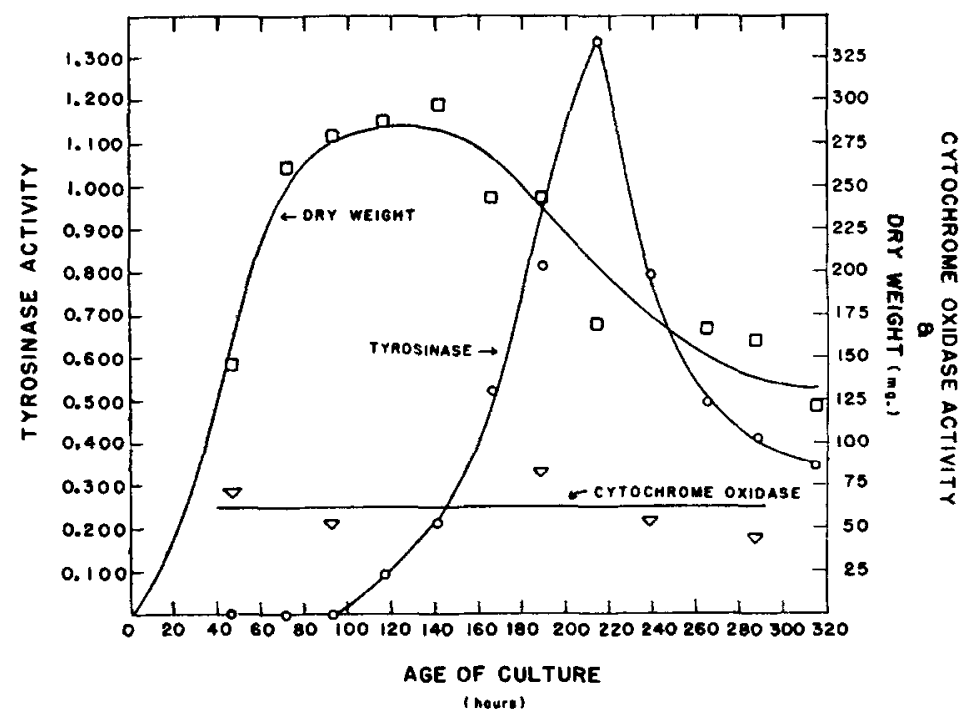

Frg. 2. The oxidase activity and dry weight changes in mutant 509 of Glomerella cingulata. Cytochrome oxidase aetivity is expressed as cu. mm. $\mathrm{O}_{2} / \mathrm{mg} . \mathrm{N}$; tyrosinase activity is expressed as $\Delta$ optical density $/ \mathrm{min} . / 100 \mu \mathrm{g}$. N. Legend: squares, dry weight; triangles, cytochrome oxidase activity; and circles, tyrosinase activity.

relationship holds even though both organisms have more tyrosinase at the peak of their activity than does the standard type. It should be noted that the curve obtained for the tyrosinase activity of mutant 300 during Expt. 2 (Fig. 3) is shifted to the left of that for Expt. 1. No growth determinations were made during Expt. 2, but it is likely that the peak of growth was reached sooner in this experiment than in Expt. 1 because the Petri dishes contained less than $30 \mathrm{ml}$. of growth medium. As in the case of the standard strain, the formation of color in the mycelium parallels the development of tyrosinase activity. 
Finally, the oxidase activity of two tyrosinase-less mutants (207 and 550) was studied, and the results are summarized in Table IV. As in the case of the other mutants, cytochrome oxidase activity remained essentially constant. Although there is considerable scatter in the data, there is the suggestion of an increased amount of cytochrome oxidase in mutant 207 as compared with other mutants. There is almost no tyrosinase activity in either of these mutants, but the slight activity which does occur appears first, as in the other mutants, after the peak of growth has been reached.

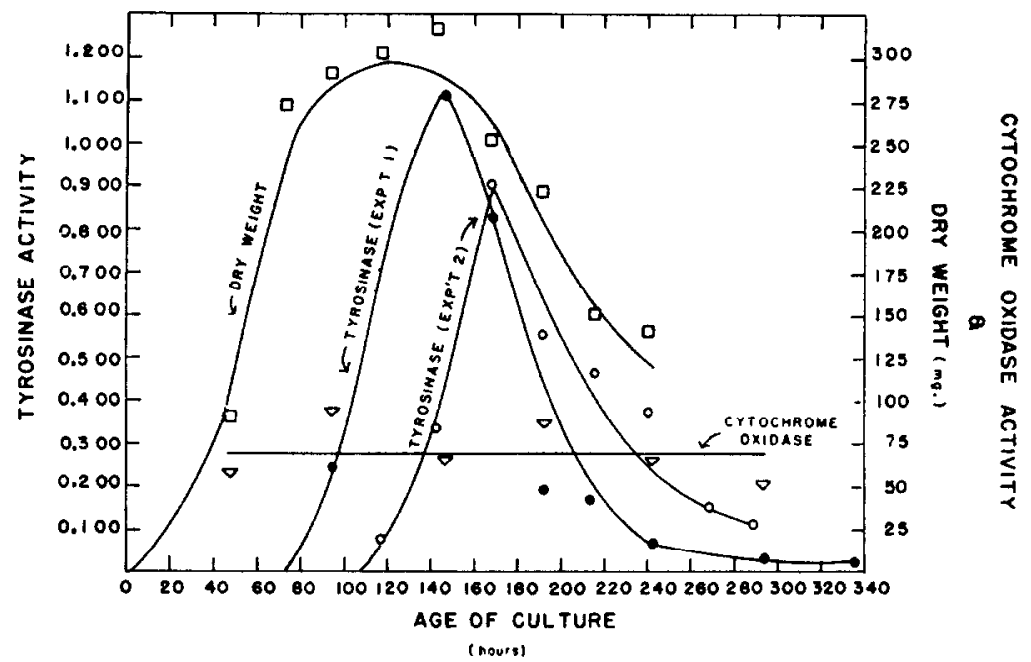

Fra. 3. The oxidasc activity and dry weight changes in mutant 300 of Glomerella cingulata. Cytochrome oxidase activity is expressed as cu. $\mathrm{mm} . \mathrm{O}_{2} / \mathrm{mg} . \mathrm{N}$; tyrosinase activity is expressed as $\Delta$ optical density/min./100 $\mu \mathrm{g}$. N. Legend: squares, dry weight; triangles, cytochrome oxidase activity (Expt. 2); circles (filled), tyrosinase activity (Expt. 1); and circles (open), tyrosinase activity (Expt. 2).

The possibility remained that tyrosinase was present in the latter two mutants but that its activity was inhibited by the presence of substances like the sulfhydryl-containing compounds described by Horowitz and Shen (5). Therefore, substances which combine with sulfhydryl groups were added to the enzyme preparations in order to nullify the action of these inhibitors. For this purpose, $p$-chloromercuribenzoic acid and phenylmercuribenzoic acid were used, but they did not increase enzyme activity. Moreover, vigorous aeration, which might help to oxidase sulfhydryl compounds, did not influence the results. Finally, dialysis in 
the cold, against the extraction medium, did not induce activity in any of the several inactive preparations tried.

TABLE IV

Oxidase Activity and Dry Weight Changes in Mutants 207 and 550 of Glomerella cingulata

\begin{tabular}{|c|c|c|c|c|}
\hline Mutant & Age & $\begin{array}{l}\text { Dry wt. } \\
\text { (1 Petri dish) }\end{array}$ & $\begin{array}{c}\text { Cytochrome } \\
\text { oxidase activity }\end{array}$ & Tyrosinase activity ${ }^{a}$ \\
\hline \multirow{8}{*}{ W207 } & $h r$. & $m g$. & $c u . m m . O_{2} / m g . N$ & $\begin{array}{c}\Delta \text { opt.dens./min./ } \\
100 \mathrm{\mu g} . \mathrm{N}\end{array}$ \\
\hline & 46 & 106 & 112 & 0 \\
\hline & 94 & 315 & 70 & + \\
\hline & 148 & 287 & 60 & $+t$ \\
\hline & 192 & 255 & 93 & +++ \\
\hline & 242 & 142 & 98 & $++t$ \\
\hline & 265 & 170 & 101 & ++ \\
\hline & 527 & - & - & 0 \\
\hline \multirow[t]{7}{*}{ W550 } & 46 & 77 & 34 & 0 \\
\hline & 94 & 240 & 61 & + \\
\hline & 148 & 275 & 49 & ++ \\
\hline & 192 & 285 & 71 & $+t+$ \\
\hline & 242 & 174 & 93 & $+t+$ \\
\hline & 265 & 129 & 81 & ++ \\
\hline & 527 & - & - & 0 \\
\hline
\end{tabular}

a In all cases tyrosinase activity was too low to be measured by the spectrophotometric assay. Therefore the results are expressed as discussed under Methods.

\section{Discussion}

The conclusion seems inescapable that cytochrome oxidase is present at all times during the growth of each of the mutants of Glomerella cingulata that were tested. Its activity remains fairly constant during the entire development of the fungus although there is the possibility that the conidia possess more of the enzyme. Similarly, mutant 207 appears to have somewhat more cytochrome oxidase activity than do the other mutants tested.

This enzyme seems to be localized on granules which sediment in 20 min. in centrifugal fields varying from 5000 to $18,000 \times g$. Although the staining reactions of these granules were not studied, they were observed under the microscope using both phase and ordinary optics. Under these conditions they were noted to be between $1-3 \mu$ in size and spherical in shape. Results obtained using the electron microscope verified these 
observations. Therefore, the morphology and enzymatic activity of these particles parallel those of mitochondria isolated from other sources (6).

Tyrosinase activity, on the other hand, undergoes rather striking variations in activity. Conidia possess moderate enzyme activity but lose this within $48 \mathrm{hr}$. after germination. At $120 \mathrm{hr}$., tyrosinase activity begins to appear and reaches a maximum about $40 \mathrm{hr}$. thereafter. The initiation of tyrosinase activity in the mycelium coincides with the end of growth or with the beginning of the autolysis of the mycelium. These results suggest that an induced synthesis of tyrosinase occurs (7), possibly in response to the accumulation of a substance released during autolysis. Since conidia are produced during the time when tyrosinase has already been formed in the mycelium ( $200 \mathrm{hr}$. after inoculation), the presence of this enzyme in the conidia is not surprising. The loss of tyrosinase upon the germination of conidia may be due to an actual destruction of the enzyme or to its dilution as growth progresses. A rapid decrease in tyrosinase activity occurs after the peak in this enzymo's activity is reached. Since rapid growth is certainly not occurring at this time, dilution of the enzyme does not occur and actual destruction must take place.

In contrast to cytochrome oxidase, tyrosinase activity seems to be associated with the soluble components of the cell, or with particles which do not sediment within $30 \mathrm{~min}$. at $18,000 \times g$. These results agree with those of Goddard and Holden (3) who worked with potatoes, as well as with the results of others who have used a variety of materials (6).

It has been proposed for other organisms containing tyrosinase, that this enzyme functions as a terminal oxidase in respiration (8). This possibility can be eliminated in the case of Glomerella cingulata, for tyrosinase is absent during the period of most rapid growth. The fact that the amount of growth of the tyrosinase-less mutants is almost equal to that of the ones having this enzyme also supports this view. Finally, these data suggest that tyrosinase synthesis is independent of cytochrome oxidase synthesis in Glomerella.

\section{ACKNOWLEDGMENTS}

The authors wish to acknowledge the able assistance of Miss Patricia A. Caughey. This investigation was aided by grants-in-aid from the U. S. Atomic Energy Commission and from the American Cancer Society upon recommendation of the Committee on Growth of the National Research Council. 


\section{Summary}

Cytochrome oxidase activity in the standard type and in four mutants of Glomerella cingulata has been shown to be constant throughout the mycelial development. This enzyme is concentrated on mitochondria-like particles which are extractable in hypertonic solutions of disaccharides. On the other hand, tyrosinase activity is concentrated in the supernatant and changes markedly during the development of the organism. This enzyme is present in the standard type and in two of the mutants, while the other two mutants have only minimal amounts. In the mycelia having such activity, tyrosinase increases precipitously, after the peak of growth has been reached, and then declines almost immediately, although small amounts of tyrosinase remain in the mycelium for as long as it is possible to obtain extracts. The evidence suggests that tyrosinase cannot function as the terminal oxidase during growth, although cytochrome oxidase can function in this way.

\section{REFERENCES}

1. Ephrussi, B., And Slonimsky, P. P. Biochim. et Biophys. Acta 6, 256-7 (1950).

2. Markert, C. L. Genetics 35, 60-75 (1950).

3. Goddard, D. R., and Holden, C. Arch. Biochem. 27, 41-7 (1950).

4. Косн, L. H., and McMeekin, T. L. J. Am. Chem. Soc. 46, 2066 (1924).

5. Horowitz, N. H., And Shen, S. J. Biol. Chem. 197, 513-20 (1952).

6. Dounce, A. L., in Sumner and Myrback, eds. The Enzymes, Vol. 1, part 1, p. 195. Academic Press, New York, 1950.

7. Monod, J., And Cohn, M. Advances in Enzymol. 13, 67-119 (1952).

8. Sussman, A. S. Quart. Rev. Biol. 24, 328-41 (1949). 